\title{
Reconstruction of a scalp defect due to cochlear implant device extrusion using a temporoparietal fascia flap and a split-thickness skin graft from the scalp
}

\author{
Jae Kyoung Kang ${ }^{1}$, \\ Jae Seong Lee', \\ Michelle Suh', \\ Gil Chae Lim, \\ Myoung Soo Shin ${ }^{1}$, \\ Byung Min Yun ${ }^{1}$ \\ ${ }^{1}$ Department of Plastic and \\ Reconstructive Surgery, Jeju National \\ University College of Medicine, Jeju; \\ ${ }^{2}$ Department of Plastic and \\ Reconstructive Surgery, Jeju National \\ University Hospital, Jeju; ${ }^{3}$ Department \\ of Otorhinolaryngology, Jeju National \\ University College of Medicine, Jeju, \\ Korea
}

\begin{abstract}
Cochlear implant extrusion, which is a common complication of cochlear implants, is generally repaired by a well visualized soft-tissue flap. A 61-year-old female patient with a medical history of schizophrenia who had a skin ulcer that caused cochlear implant extrusion, but that would be a stronger statement was referred to our department for removal of the implant and reconstruction of the resultant scalp defect. Accordingly, the broad defect was covered via rotation of a temporoparietal fascia flap (TPFF) using the superficial temporal artery, with the pedicle in the preauricular region as the pivot point. Coverage of TPFF was achieved with a split-thickness skin graft using the scalp as the donor site, which led to a quick recovery after the operation and satisfactory results in terms of aesthetics. This case suggests that a TPFF might be used as a flexible flap with low donor site morbidity for reconstructing cases of cochlear implant extrusion accompanied by a large full-layer scalp defect.
\end{abstract}

Keywords: Cochlear implants / Reconstructive surgical procedures / Surgical flaps

\section{INTRODUCTION}

Cochlear implants are being used as the latest treatment for sensorineural hearing loss. Wound breakdown is a common complication after cochlear implantation, occurring in up to $10 \%$ of cases. The causes of wound breakdown include an incorrect direction of the incision upon implantation, infection, skin flap necrosis, and external pressure on the implant site [1]. Cochlear implant extrusion can be reconstructed using various methods, including but not limited to primary closure, postau-

\footnotetext{
Correspondence: Byung Min Yun

Department of Plastic and Reconstructive Surgery, Jeju National University College of Medicine, 102 Jejudaehak-ro, Jeju 63243, Korea

E-mail: almostfree@hanmail.net

This work was supported by the 2019 education, research and student guidance grant funded by Jeju National University.

Received July 19, 2019 / Revised August 16, 2019 / Accepted September 16, 2019
}

ricular pedicled flaps, scalp rotational flaps, pericranial flaps, anterolateral thigh flaps, and pedicled temporalis muscle flaps [2].

The temporoparietal fascia flap (TPFF) has the advantages of versatility, pliability, and a wide rotational arc of the pedicle. It is very useful for derencephalus reconstruction [3]. However, few cases of reconstruction of cochlear implant extrusion have been reported since the first use of the TPFF for this purpose by Beckenstein et al. [4] in 1999. In previous studies, cochlear implant extrusion was covered by a TPFF. The area of ulcerated skin was reconstructed using primary closure or a scalp rotation flap, as the ulcers were small.

This paper presents the case of a 61-year-old female patient with a full-layer scalp defect that was larger $(5 \times 6 \mathrm{~cm})$ than has been discussed in previous studies. Her cochlear implant was exposed as a complication of a skin ulcer and infection. The re- 
sulting defect was successfully reconstructed using a TPFF and a split-thickness skin graft (STSG) with the scalp as the donor site.

\section{CASE REPORT}

A 61-year old female patient with schizophrenia underwent otolaryngologic treatment for a skin ulcer at the recipient site of a cochlear implant on her right side. The patient had undergone right cochlear implantation 10 years previously, and in the most recent 2 to 3 years had experienced breakdown of the cochlear implant, scalp necrosis, and the consequent development of a defect. Bacterial culture was conducted at the skin ulcer site, and Streptococcus agalactiae was found. A biopsy was conducted and infected granulation tissue was found. Accordingly, the decision was made to remove the receiver. She was referred to our department for reconstruction of the resultant scalp defect.

The incision line was designed after determining the direction of the superficial temporal artery by preoperative computed tomography angiography and Doppler ultrasonography. The operation was conducted under general anesthesia. The TPFF was sufficiently exposed after the incision of a question-mark shape with access to the lower layer of the hair follicles (Fig. 1). The length of the axis was set to cover the skin defect by rotation of the pre-tragus region as the pivot point. The sites to be elevated, including the parietal branch of the superficial temporal artery, were marked with a skin marker. Avoiding any damage to the pedicle vessel, the loose areolar tissue between the deep temporal fascia and superficial temporal fascia was dissected. Implant removal and infected tissue debridement were conducted at the department of otolaryngology. A skin defect measuring $5 \times 6 \mathrm{~cm}$ developed, and the skull was exposed. The dura was confirmed to be intact. A pedicled TPFF was elevated and rotated, using

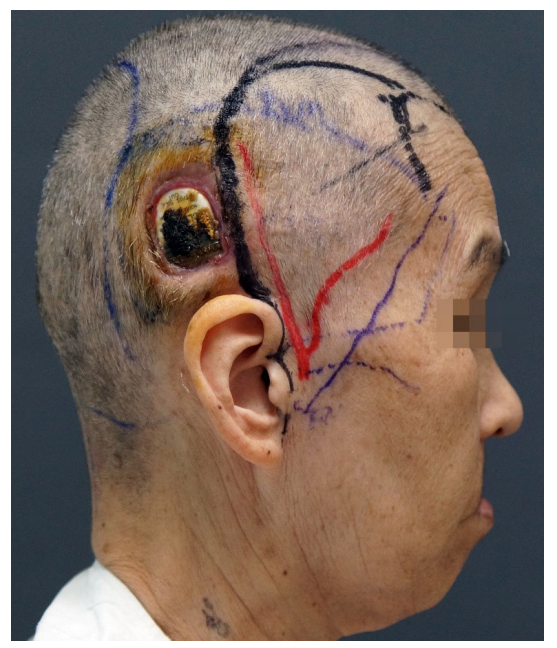

Fig. 1. Flap design. the pre-tragus region as the pivot point (Fig. 2). The TPFF was fixed at the scalp flap, surrounding the defect (Fig. 3). Vaseline gauze was placed between the stiches to avoid leaving any stitch marks. STSG with the scalp in the left parietal area as the donor site was conducted on the TPFF-rotated site (i.e., at the site of the skin defect). After designing the scalp site to be used for collection, saline with epinephrine (dilution: 1:1,000,000) was injected to inflate the scalp (Fig. 4). A dermatome was used to collect a 0.2 -mm-thick graft layer, and bleeding from the donor site was stopped immediately after collection by using gauze soaked with epinephrine. The skin was placed on the recipient site prepared by a tie-over dressing.

The donor site region of the scalp was epithelized on postoperative day 6 . The tie-over dressing was opened on postopera-

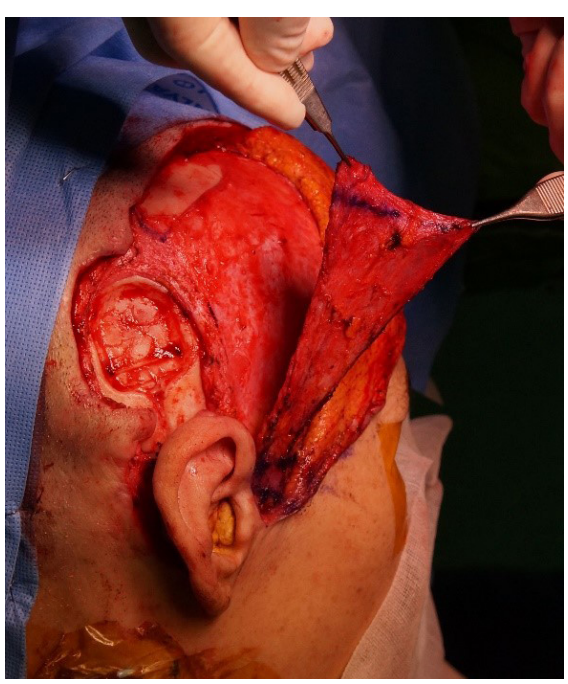

Fig. 2. Elevated flap.

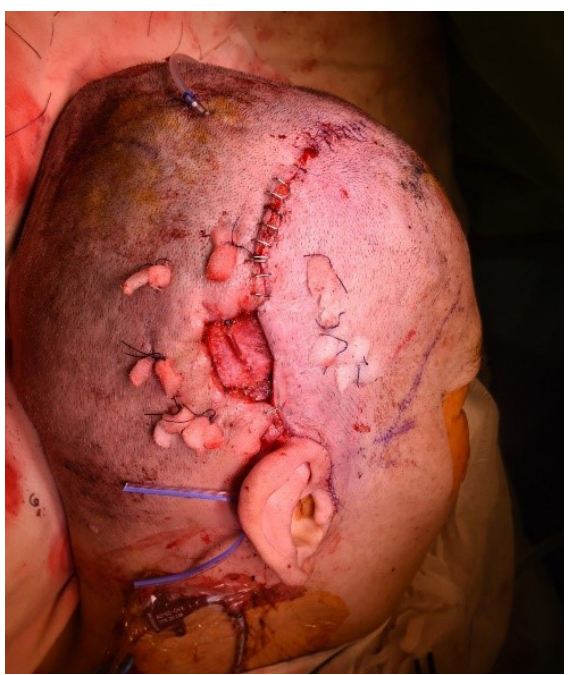

Fig. 3. Fixation of the temporoparietal fascia flap to the scalp around the defect. 


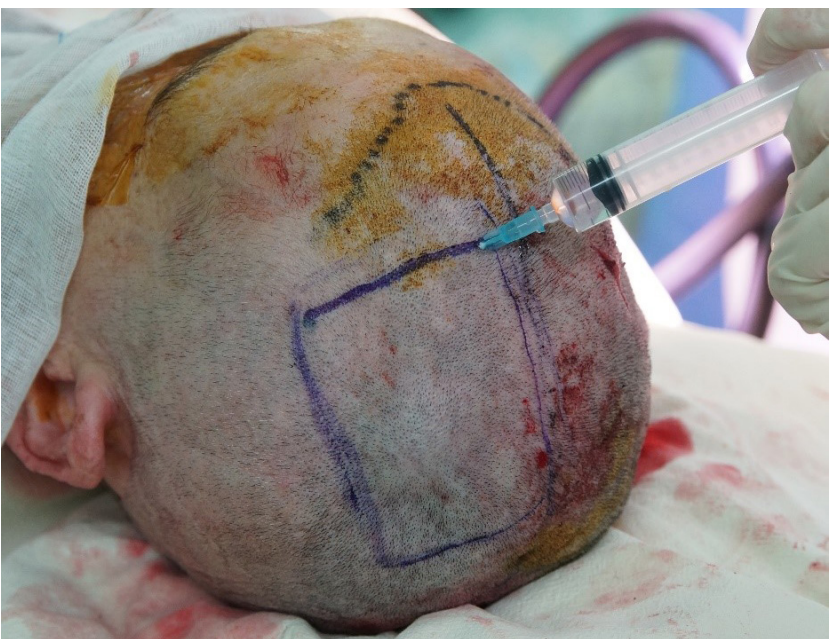

Fig. 4. Skin harvesting after infiltration of saline with diluted epinephrine.

tive day 7. Engrafting was successful without any graft loss. During a 5-month follow-up period, the wound healed without any complications (Fig. 5).

\section{DISCUSSION}

Cochlear implants are a safe and effective treatment for severe sensorineural hearing loss. Common non-device related complications include skin flap necrosis, infection, dehiscence, and device extrusion in $1.7 \%$ to $10 \%$ of cases $[1,5]$. Migration of skin tension and the device caused by the bulk of the receiver can lead to flap erosion as a possible cause of implant extrusion. Additional causes of implant extrusion include consistent external pressure on the implant site, old age, use of steroids, radiotherapy, anticancer therapy, and smoking $[5,6]$. According to previous studies, using an anteriorly-based C-shaped flap for cochlear implantation can block the blood supply from the occipital artery, causing flap-related complications. Therefore, an inferiorly-based U-shaped flap is often recommended [5]. The use of intravenous antibiotics is recommended in cases where the tissue surrounding the device becomes infected or the device is exposed. If the affected area is wide, new device implantation and scalp reconstruction are required after removal of the previous device [7]. In the present case, the patient's old age and unawareness of the infection over 2 to 3 years due to schizophrenia might have aggravated the implant extrusion.

The elasticity of the scalp is limited due to the underlying galea and pericranium. In general, primary closure can be an option for small and flat defects $\left(<2 \mathrm{~cm}^{2}\right)$, while a local flap is required for defects measuring $2-25 \mathrm{~cm}^{2}$ [8]. Reconstruction could be conducted using a free flap if the flap condition is poor or if the defect is too large [9]. For severe defects that develop

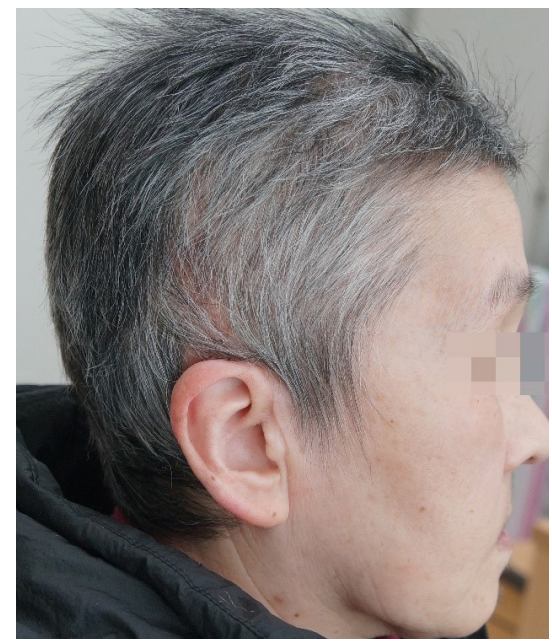

Fig. 5. Photograph at 5 months postoperatively.

after cochlear implantation, a temporalis myofascial flap might be used $[5,10]$. Otherwise, two-stage surgery using an anterolateral thigh flap or tissue expander can be conducted [5].

The TPFF described in this case report was initially used by Brown in 1898 for reconstruction of ears using the superficial temporal artery as the pedicle. It is thin, flexible, and easily visualized. Thus, it has also been used in reconstruction of the head and neck [3]. It is used both for eyebrow reconstruction [11] with a tunneled fasciocutaneous hair-bearing flap, and for the reconstruction of non-hair-bearing defects, such as those on the eyelid or nasal ala, with a superficial temporal arterybased preauricular island flap [12]. The TPFF has been introduced as a method to reconstruct cochlear implant extrusion due to its low morbidity at the donor site and anatomical proximity to the implant insertion site. The accompanying scalp defect could be reconstructed using a local flap after covering the extrusion site with a TPFF.

In the present case, the infection site was wide, and a relatively large full-thickness defect $(5 \times 6 \mathrm{~cm})$ developed after removal of the implant. It was too large to cover with primary closure or a rotational local flap. The use of a superficial temporal arterybased V-Y flap [13] or an occipital artery-based V-Y flap in wide scalp defects has been reported [14]. The V-Y flap has the advantage of being hair-bearing, compared to skin grafts. However, it has a substantial risk of distortion, and concerns exist regarding postoperative flap and donor site healing in patients with mental illnesses and/or senility, similarly to the issues that arise for free flaps. The exposed skull was covered by a TPFF. A STSG was collected from the donor site on the opposite side of the parietal scalp.

The scalp, which was first used as the donor site for a splitthickness skin graft by Crawford in 1964 [15], has various ad- 
vantages as a donor site. One of its advantages is its rapid recovery compared to other donor sites. According to a literature review, the recovery period of the scalp is 5-6 days, compared to 2 weeks for other donor sites [16]. This is due to the high density of hair follicles and the presence of an abundant blood supply to the scalp [17]. The rapid recovery of the scalp enables several rounds of repeated harvesting for skin implantation in patients with extensive burns. In addition, using the scalp as a donor site does not leave any scar, and causes less postoperative pain compared to other sites [17]. The disadvantages of the scalp as a donor site are more bleeding upon harvesting and potential alopecia at the donor site [18]. Bleeding can be reduced by using vasopressors. Alopecia can be prevented by harvesting grafts that are less than $0.5 \mathrm{~mm}$ thick and avoiding exceeding an average depth of $2.63 \mathrm{~mm}$. Scalp-donor STSG are easier to be used for reconstructing scalp defects because the operation can be conducted at a single site. Rapid recovery helped our patient, who had a medical history of schizophrenia at the age of 61 and was sensitive to pain, to maintain mental stability. During 5 months of follow-up, the patient's alopecia became unremarkable as her hair grew.

In conclusion, this case shows that a large scalp defect could be reconstructed in a relatively easy and safe way, in a short period of time, by using a TPFF with minimal donor morbidity and anatomical proximity to the cochlear implant site combined with a STSG for which the scalp was the donor site.

\section{NOTES}

\section{Conflict of interest}

No potential conflict of interest relevant to this article was reported.

\section{Ethical approval}

The study was approved by the Institutional Review Board of Jeju National Hospital (IRB No. JEJUNUH 2019-06-018) and performed in accordance with the principles of the Declaration of Helsinki. Written informed consent was obtained.

\section{Patient consent}

The patient provided written informed consent for the publication and the use of her images.

\section{ORCID}

Jae Kyoung Kang

Jae Seong Lee

https://orcid.org/0000-0003-3547-6845

Michelle Suh

https://orcid.org/0000-0002-0087-8791

Gil Chae Lim
Myoung Soo Shin https://orcid.org/0000-0002-8450-821X

Byung Min Yun https://orcid.org/0000-0002-3545-4446

\section{REFERENCES}

1. Ramos A, Charlone R, de Miguel I, Valdivielso A, Cuyas JM, Perez D, et al. Complications in cochlear implantation. Acta Otorrinolaringol Esp 2006;57:122-5.

2. Karimnejad K, Akhter AS, Walen SG, Mikulec AA. The temporoparietal fascia flap for coverage of cochlear reimplantation following extrusion. Int J Pediatr Otorhinolaryngol 2017;94:647.

3. Collar RM, Zopf D, Brown D, Fung K, Kim J. The versatility of the temporoparietal fascia flap in head and neck reconstruction. J Plast Reconstr Aesthet Surg 2012;65:141-8.

4. Beckenstein MS, Steenerson RL, Elliott LF, Hartrampf CR Jr. Use of a superficial temporal fascia flap for coverage of an exposed cochlear implant. Otolaryngol Head Neck Surg 1999; 120:940-2.

5. Geraghty M, Fagan P, Moisidis E. Management of cochlear implant device extrusion: case series and literature review. J Laryngol Otol 2014;128 Suppl 2:S55-8.

6. Leach J, Kruger P, Roland P. Rescuing the imperiled cochlear implant: a report of four cases. Otol Neurotol 2005;26:27-33.

7. Roland JT Jr, Huang TC, Cohen NL. Revision cochlear implantation. Otolaryngol Clin North Am 2006;39:833-9.

8. Leedy JE, Janis JE, Rohrich RJ. Reconstruction of acquired scalp defects: an algorithmic approach. Plast Reconstr Surg 2005;116:54e-72e.

9. Newman MI, Hanasono MM, Disa JJ, Cordeiro PG, Mehrara BJ. Scalp reconstruction: a 15-year experience. Ann Plast Surg 2004; 52:501-6.

10. Eun SC, Kim SY, Kim CS, Koo JW. Temporalis myofascial flap coverage for extrusion of internal device after cochlear implantation. Int J Pediatr Otorhinolaryngol 2016;91:124-7.

11. Motomura H, Muraoka M, Nose K. Eyebrow reconstruction with intermediate hair from the hairline of the forehead on the pedicled temporoparietal fascial flap. Ann Plast Surg 2003;51: 314-8.

12. Yamauchi M, Yotsuyanagi T, Yamashita K, Ikeda K, Urushidate S, Mikami M. The reverse superficial temporal artery flap from the preauricular region, for the small facial defects. J Plast Reconstr Aesthet Surg 2012;65:149-55.

13. Tenna S, Brunetti B, Aveta A, Poccia I, Persichetti P. Scalp reconstruction with superficial temporal artery island flap: clinical experience on 30 consecutive cases. J Plast Reconstr Aesthet Surg 2013;66:660-6.

14. Sharma RK, Tuli P. Occipital artery island V-Y advancement 
flap for reconstruction of posterior scalp defects. J Plast Reconstr Aesthet Surg 2010;63:410-5.

15. Crawford BS. An unusual skin donor site. Br J Plast Surg 1964;17:311-3.

16. Berkowitz RL. Scalp-in search of the perfect donor site. Ann Plast Surg 1981;7:126-7.
17. Taylor JW, Wilmore DW, Peterson HD, Pruitt BA Jr. Scalp as a donor site. Am J Surg 1977;133:218-20.

18. Brou J, Vu T, McCauley RL, Herndon DN, Desai MH, Rutan RL, et al. The scalp as a donor site: revisited. J Trauma 1990;30: $579-81$. 